\title{
Soft budget constraint in health care: evidence from Italy
}

\author{
Rosella Levaggi and Francesco Menoncin
}

October 28, 2010

\begin{abstract}
The reforms that have reshaped most public health care system have often been accompanied by a process of devolution. However, this process has not always produced the desired effects and the existence of widespread soft budget constraint policies at local level is well documented. In this paper we argue that the soft budget constraint arises from a cooperative game between the authorities that are locally responsible for both the provision and the finance of health care. Our theoretical model is tested using data for Italian Regions for the period 2002-2006 and our hypothesis is verified. Although the model uses Italy as a benchmark, the results can be easily extended to any federal context where resources are unevenly distributed and preferences are asymmetric.

Keywords: Soft budget constraint, health care provision, patients' mobility
\end{abstract}

J.E.L. I18,H77 


\section{Introduction}

The reforms that have reshaped most public health care system have often been accompanied by a process of devolution. However, this process has not always produced the desired effects and the existence of widespread soft budget constraint policies at local level is well documented. In Italy, the regional health care deficit has reached 3200 millions of Euros in 2007; Medicaid expenditure in the US is becoming a serious concern for the Federal State (Marton and Wildasin, 2007) and the evidence from other Federal States is not reassuring (Crivelli and Staal, 2008). The literature on soft budget constraint mainly deals with bailing out firms that run into deficit ${ }^{1}$. Crivelli and Staal (2008) and Wildasin (2004) propose two of the few theoretical models of bailing out at local government level. Both papers assume the existence of neighbour local authorities that produce local public goods. However, the good produced by one local authority $(B)$ spills its beneficial effect also to residents of the other local authority $(A)$. In the model proposed by Wildasin a possible equilibrium is one where either Central Government or Authority $A$ provides the local public good in $B$ and finances such provision, but the quantity is suboptimal. Instead, Crivelli and Staal focus on the game between Central and Local Governments and show that if the local public good produces spillovers the local government might shift some of its fiscal burden to the upper tier through a soft budget constraint policy. Levaggi and Zanola (2003) and Bordignon and Turati (2009) show empirical evidence for the soft-budget constraint. In both cases the focus is on expenditure rather than explanation of the soft budget constraint itself.

In this paper we argue that the soft budget constraint arises from a cooperative game between the authorities that are locally responsible for the provision and finance of health care. The application of fiscal federalism to health care produces undesired effects that the literature has so far overlooked. Richer local authorities have an incentive in controlling the supply and distribution of health care expenditure owing to the effects on their tax bill of equalisation grants. On the other hand, poor local authorities that are the potential losers of the federalist process may strategically decide to be bailed out by Central Government (Wildasin, 1997).

This process produces two clear losers:

1. the whole community, which would be better-off if hard budget constraint rules were imposed;

2. the users of the services in the regions where soft budget constraint is widespread who have to travel and incur private costs.

Our model uses Italy as a benchmark because this country presents all the ingredients of the policy we want to analyse, but the results can be easily extended to any federal context where resources are unevenly distributed and preferences are asymmetric.

\footnotetext{
${ }^{1}$ See Maskin and $\mathrm{Xu}(2001)$ and Rodden et al. (2003) for a review.
} 
The paper is organised as follows: in Section 2 we present the peculiar characteristics of the soft budget constraint in Italy as a case study, in Section 3 the model is presented, Section 4 presents the econometric estimation of our model and Section 5 draws the conclusions.

\section{Soft budget constraint in Italy}

Health care provision in Italy represents a very good example of fiscal federalism in a problematic context. Income is unevenly distributed across regions, and great proportion of expenditure through grants-in-aid ${ }^{2}$. Ferrario and Zanardi, (2009) estimate that the redistributive impact of health care is about $7-9 \%$ of total GDP. In Italy the regionalisation of health care expenditure is characterized by two important facts: some regions persistently run into deficit; patient mobility across regions is fairly well-developed.

\section{FIGURE 1 ABOUT HERE}

In figure 1 the relationship between mobility balances and deficit is presented. The correlation is positive: most of the Regions with a deficit also have a negative balance as regards health care. ${ }^{3}$ The mobility of patients follows quite interesting patterns: in some cases (Trento, Bolzano, Valle d'Aosta, Abruzzo, Molise, Umbria) it depends on economies of scale. Small regions are not able to produce all the services locally and prefer to specialise in a few of them; through mobility they are then able to supply health care to all their population. In this case, mobility is concentrated among adjacent regions, and it is usually two-sided. The balance (i.e. the difference between patients treated outside the Region and patients coming from other Regions) is usually rather limited: the inflows are quite similar to the outflows. This behaviour can be consistently explained by the theory of fiscal federalism ${ }^{4}$ : it corresponds to spillovers in the production of health services. However, only a limited part of the mobility flow can be explained by this mechanism: most of it is represented by a one-sided flow of patients from southern Regions (running into a deficit) to northern Regions. These regions that run into deficit heavily rely on grants from Central Government to finance health care (about $75 \%$ against a national average of $55 \%$ ) because their tax base is fairly low compared to the national tax base. In the next sections we propose a model that explains this evidence.

\footnotetext{
${ }^{2}$ On average about $40 \%$ of public health care at regional level if financed out of local taxation. For some regions it may be as low as $20 \%$.

${ }^{3}$ The only important exception is Lazio, but the behaviour of this region has been dominated by other factors.

${ }^{4}$ See Oates (2005) and Tresch (2002).
} 


\section{The model}

Levaggi and Menoncin (2009) show that fiscal federalism, in the context of merit/impure local public goods with spillovers, may produce welfare losses because spillovers may not be correctly evaluated. However, although total welfare is decreasing, fiscal federalism may produce a welfare improvement for some local authorities (the richest ones) because it may reduce the pressure for equalisation of resources. This means that a cooperative solution to internalise such externalities may not be feasible. In this paper we show how a cooperative solution involving soft budget constraint may instead arise using the basic assumptions of model presented in Levaggi e Menoncin (2009). We assume that health care is to spurious merit good with spillovers (Besley and Coate, 2003; Crivelli and Staal, 2008; Wildasin, 1997) which is supplied for free or through the payment of a limited fee, but only if the treatment is cost effective. ${ }^{5}$

A country is divided into two Local Authorities $i \in\{A, B\}$. The total welfare of each Authority is assumed to be the linear combination of three components.

1. Net money income. Each local authority has a total base equal to $Y_{i}$; taxes are levied by both the Central Government $(t)$ and the Local Authority $\left(\tau_{i}\right)$. Accordingly, net income is given by $Y_{i}\left(1-t-\tau_{i}\right)$. We assume that $Y_{A}>Y_{B}$

2. Utility from consuming health care. Each Region has a mass of individuals, normalised to $1 / 2$, fully described by $\alpha$,their utility ${ }^{6}$ for health care. This parameter is uniformly distributed in the range $[0, \beta]$. The local authority is willing to supply care only if utility is higher than a given threshold $\left(b_{i}\right)$ that it will be optimally chosen in order to maximize the total welfare of its citizens. Furthermore, since we assume that the demand is equally shared between the two regions, we have

$$
Q_{i}=\frac{1}{2} \int_{b_{i}}^{\beta} \frac{1}{\beta} d \alpha=\frac{\beta-b_{i}}{2 \beta} .
$$

In each Region the agents' utility from consuming $Q_{i}$ (let us call it $u_{i}\left(Q_{i}\right)$ ) is given by the amount of health care consumed multiplied by the preference parameter $\alpha$. Accordingly, we have

$$
u_{i}\left(Q_{i}\right)=\frac{1}{2} \int_{b_{i}}^{\beta} \alpha \frac{1}{\beta} d \alpha=\frac{\beta^{2}-b_{i}^{2}}{4 \beta} .
$$

\footnotetext{
${ }^{5}$ The basic difference between a merit good and an impure public good is that the former is in fact a private good that is used to improve income redistribution or to pivot consumers' preferences towards the use of goods which the planner thinks they should use. We define as spurious merit good a class of services that have this double characteristic, for example health, education and cultural activities.

${ }^{6}$ In this context we assume that the utility received from health care is related to the personal ability of each individual to recover health from care. In this sense it may be also interpreted in terms of productivity of health care.
} 
3. Finally, the health care produces a public good that depends on the quantity produced in each Region $\left(S_{i}\right)$, i.e. the health care is a local public good with spillovers ${ }^{7}$ Although total demand $Q_{A}+Q_{B}$ must be equal to the total supply $S_{A}+S_{B}$, we allow for mobility, i.e. some patients may be treated outside their Region. Preferences for the public good are additive within each Local Authority:

$$
f_{i}\left(S_{i}\right)+g_{i}\left(S_{j}\right), i, j \in\{A, B\},
$$

where both functions $f(\cdot)$ and $g(\cdot)$ are assumed to be increasing and concave with $0<g_{i}<f_{i}$. Here $f_{i}$ measures the local public good aspect of health care (due to the treatment produced within the Region) while $g_{i}$ measures the spillover effect (arising from total supply outside the Region). There are no fixed production costs for $S_{i}$ and the marginal cost is given by $v_{i}$ with $v_{A}<v_{B}$ (i.e. the richest Region is also the most efficient).

The total welfare for Local Authority $i$ can accordingly be written as

$$
W_{i}=Y_{i}\left(1-t-\tau_{i}\right)+\frac{\beta^{2}-b_{i}^{2}}{4 \beta}+f_{i}\left(S_{i}\right)+g_{i}\left(S_{j}\right),
$$

with $i, j \in\{A, B\}$ and $i \neq j$.

The financing of health care production and the spillovers are different whether the budget constraint is hard or soft. In the next sections we present both cases.

\section{Fiscal federalism: hard budget constraint}

In a framework where each Region can decide to freely set its expenditure level, the role of Central Government (CG) is confined to regulate the market and to set the rules for grant equalisation. CG levies a uniform income tax and pays equalisation grants $\left(G_{i}\right)$ which are distributed in a lump-sum form as suggested by Dahlby and Wilson (1994) and Smart (1998). Accordingly, the CG budget constraint can be written as (see also Petretto, 2000)

$$
t\left(Y_{A}+Y_{B}\right)=G_{A}+G_{B},
$$

where

$$
G_{i}=\frac{1}{2} \tau_{m}\left(\bar{Y}-Y_{i}\right),
$$

with $\tau_{m}$ representing the national average surtax rate

$$
\tau_{m} \equiv \frac{\tau_{A} Y_{A}+\tau_{B} Y_{B}}{Y_{A}+Y_{B}}
$$

and $\bar{Y}$ being the average revenue

\footnotetext{
${ }^{7}$ See Besley and Coate (2003)
} 


$$
\bar{Y} \equiv \frac{Y_{A}+Y_{B}}{2} .
$$

Both $G_{i}$ are invariant to each regional fiscal decision, i.e. local authorities do not perceive the effects that their tax rate has on the equalisation grant.

Health care used by residents in one region but produced outside has a price $q$. For this reason, the Local Authority budget constraint can be written as:

$$
\tau_{i} Y_{i}+G_{i}=v_{i} S_{i}+q\left(Q_{i}-S_{i}\right) .
$$

In this framework, each local authority sets its own level of taxation and service production according to its preferences and resources. It takes $t$ and $G_{i}$ as given, and perceives its budget constraint as hard. Central Government's role is merely confined to equalising resources through the lump-sum grant; this actor is the last one to move, i.e. it sets the grant after local authorities have set their own level of expenditure and taxation. Local authorities have the maximum degree of autonomy and we denote it by "fiscal federalism".

The problem faced by each local authority can be written as

$$
\begin{gathered}
\max _{b_{i}, S_{i}} Y_{i}\left(1-t-\tau_{i}\right)+\frac{\beta^{2}-b_{i}^{2}}{4 \beta}+f_{i}\left(S_{i}\right)+g_{i}\left(S_{j}\right), \\
\text { s.t. } \\
\tau_{i}=\frac{S_{i} v_{i}-q\left(S_{i}-Q_{i}\right)-G_{i}}{Y_{i}} .
\end{gathered}
$$

Once the constraint is plugged into the objective function, the two first order conditions can be written as

$$
\left\{\begin{array}{c}
b_{i}=q, \\
-v_{i}+q+f_{i}^{\prime}=0,
\end{array}\right.
$$

where $f_{i}^{\prime}$ is the derivative of $f_{i}$.

Each local authority does not take into account the spillover effect that its production creates on the neighbour jurisdiction. Furthermore, in their maximisation process they take $q$ as a given parameter, but it will be set as the (only) equilibrium level clearing the market. Given (1), the total demand is

$$
Q_{A}+Q_{B}=1-\frac{b_{A}+b_{B}}{2 \beta},
$$

and since $b_{i}=q$ because of the first equation in (3), we also have

$$
Q_{A}+Q_{B}=1-\frac{q}{\beta} .
$$

Levaggi and Menoncin (2009) show that welfare is lower than in the first best equilibrium, but this does not necessarily mean that both local authorities are worse off. Health care expenditure and the tax bill are lower than in FB. In general the first effect offsets the second, but in the presence of an equalising grant a reduction in expenditure implies that fewer resources are flowing from $A$ to $B$ in equilibrium and this income effect may, for the richer local authority, more than offset the initial loss due to underproduction. 


\section{$5 \quad$ Fiscal federalism and soft budget constraint}

In this section we show how patients' mobility may become the driving factor in determining a soft budget constraint. $A$, the richest and most efficient Region, would like both to reduce the tax bill caused by equalisation of resources and to increase its welfare. $B$, the poorest Local Authority is worse off than in a centralised system. Since health care is an essential need, $B$ may try to strategically play by either threatening to reduce the provision of health care or not increasing expenditure without a parallel increase in its tax bill. We believe that these two objectives may be combined together in interpreting the soft budget constraint. The two local authorities agree on the following strategy: $A$ accepts to receive from $B$ a specific number of patients $I$ which will be reimbursed to $A$ at a price $q$. $B$ sends these patients on the agreement that $A$ will allow $B$ to be bailed out; in other words the agreement between the two local authorities makes Central Government to supply $B$ with extra resources which however must be used to finance mobility from $B$ to $A$. We assume that if a deficit is created by mobility and if both local authorities agree that the deficit should be repaid, Central Government does so by increasing the national tax level $t$.

In this framework, each local authority sets its own level of taxation and service production according to its preferences and resources. It takes $G_{i}$ as given, but it perceives its budget constraint as soft. Each local authority may have a full or partial perception of the impact that the soft budget constraint policy will have on Central Government tax $t$, i.e. they may take it as fixed or they may anticipate the increase that will be necessary to repay the deficit.

\subsection{Local Authority $A$}

Local Authority $A$ is the most efficient one and, as shown in Levaggi and Menoncin (2009), is the gainer of the move from decentralisation to fiscal federalism, because the reduction in expenditure caused by the lack of coordination is more than compensated by a reduction in the tax bill caused by the reduction of the equalisation grant. In order to maintain such predominant position $A$ would like to control as much as possible the expenditure of the other local authorities. Furthermore, since the community receives utility both from consumption of health care and from its production, they can use mobility for both purposes. Through mobility $A$ controls the expenditure of the other local authority and it increases the public good aspect of such provision. It is aware that $B$ has very few incentives to cooperate and for this reason it may allow the other Local Authority to run into a deficit, provided that it is not higher than the value of mobility. In this context, $A$ has to find the level of internal consumption and mobility that maximise the welfare of its citizens.

The Local Authority $A$ must produce $Q_{A}+I$ since it also receives $I$ patients from Region $B$. Accordingly, the total cost of production for $A$ is given by $v_{A}\left(Q_{A}+I\right)$. In this case the spillovers are

$$
f_{A}\left(Q_{A}+I\right)+g_{A}\left(Q_{B}-I\right),
$$


where $Q_{i}$ are given in (1).

The revenues of $A$ are from local taxes $\left(\tau_{A} Y_{A}\right)$, CG's equalisation grant $G_{A}$, and mobility income $q I$. A's budget constrain can then be written as

$$
\tau_{A} Y_{A}+q I+G_{A}=v_{A}\left(Q_{A}+I\right) .
$$

Local Authority $A$ receives $q I$ either from $B$ or from the CG if $B$ does not pay. Let us assume that $B$ pays mobility with probability $p$, then the CG must pay $q I(1-p)$ on average. Accordingly, the new central tax level must be set in order to satisfy

$$
t\left(Y_{A}+Y_{B}\right)=G_{A}+G_{B}+q I(1-p) .
$$

Nevertheless, Local Authority $A$ could not be fully aware of the change in central taxation and if we call $\rho \in[0,1]$ the level of such a fiscal illusion, the CG's tax rate is assumed to be

$$
t=\frac{G_{A}+G_{B}}{Y_{A}+Y_{B}}+\rho \frac{q I(1-p)}{Y_{A}+Y_{B}} .
$$

The problem faced by the Local Authority $A$ can then be written as

$$
\begin{gathered}
\max _{b_{A}, I} Y_{A}\left(1-t-\tau_{A}\right)+\frac{\beta^{2}-b_{A}^{2}}{4 \beta}+f_{A}\left(\frac{\beta-b_{A}}{2 \beta}+I\right)+g_{A}\left(Q_{B}-I\right), \\
\text { s.t. } \\
\tau_{A}=\frac{v_{A}\left(\frac{\beta-b_{A}}{2 \beta}+I\right)-q I-G_{A}}{Y_{A}}, \\
t=\frac{G_{A}+G_{B}}{Y_{A}+Y_{B}}+\rho \frac{q I(1-p)}{Y_{A}+Y_{B}} .
\end{gathered}
$$

After substituting the two constraints in the objective function, the first order conditions can be easily obtained as follows

$$
\left\{\begin{array}{c}
b_{A}=v_{A}-f_{A}^{\prime}, \\
\rho q(1-p) \frac{Y_{A}}{Y_{A}+Y_{B}}+q-g_{A}^{\prime}=v_{A}-f_{A}^{\prime},
\end{array}\right.
$$

where $f_{A}^{\prime}$ and $g_{A}^{\prime}$ denote the derivatives of $f_{A}$ and $g_{A}$ respectively, with respect to their whole argument. Of course we cannot solve this system without knowing the particular functional form of both $f_{A}$ and $g_{A}$.

We stress that the first equation in (6) is exactly the same that can be obtained from combining the two equations in (3); the only difference is due to the presence of mobility.

\subsection{Local authority $B$}

The authority with higher marginal cost $(B)$ cannot attract patients from the other local authority because it is not competitive. However, given that health care is an essential need, it may try to reduce its fiscal contribution by strategically reducing health care finance. They can do so if either local authority $B$ or Central Government will bail them out (Wildasin, 1997). In this model we assume that if the deficit depends on debts that $B$ has contracted with $A$, the latter will ask Central Government to bail out $B$. 
Local Authority $B$ receives taxes $\tau_{B} Y_{B}$ and CG's grant $G_{B}$ and must pay both production costs $v_{B} S_{B}$ and mobility with probability $p$. Its budget constraint is then

$$
\tau_{B} Y_{B}+G_{B}=v_{B} S_{B}+q p I,
$$

where $S_{B}$ is given by the difference between the demand in $B\left(Q_{A}\right)$ and mobility $I$ (i.e. $S_{B}=Q_{B}-I$ ).

In this case spillovers are given by

$$
f_{A}\left(Q_{B}-I\right)+g_{A}\left(Q_{A}+I\right)
$$

where $Q_{i}$ are given in (1).

Local Authority $B$ optimally chooses how much to pay for mobility (i.e. $p$ ) and its optimal problem can be accordingly written as

$$
\begin{gathered}
\max _{b_{B}, p, I} Y_{B}\left(1-t-\tau_{B}\right)+\frac{\beta^{2}-b_{B}^{2}}{4 \beta}+f_{B}\left(\frac{\beta-b_{B}}{2 \beta}-I\right)+g_{B}\left(Q_{A}+I\right), \\
\text { s.t. } \\
\tau_{B}=\frac{v_{B}\left(\frac{\beta-b_{B}}{2 \beta}-I\right)+q p I+G_{B}}{Y_{B}}, \\
t=\frac{G_{A}+G_{B}}{Y_{A}+Y_{B}}+\rho \frac{q I(1-p)}{Y_{A}+Y_{B}} .
\end{gathered}
$$

After substituting the two constraints in the objective function, the first order conditions can be easily obtained as follows

$$
\left\{\begin{array}{l}
p=0 \\
b_{B}=v_{B}-f_{B}^{\prime}, \\
-\rho q \frac{Y_{B}}{Y_{A}+Y_{B}}-g_{B}^{\prime}=v_{B}-f_{B}^{\prime},
\end{array}\right.
$$

where the first equation comes from linearity of the objective function with respect to $p$. We have indicated with $f_{B}^{\prime}$ and $g_{B}^{\prime}$ the derivatives of $f_{B}$ and $g_{B}$ respectively, with respect to their whole argument. Of course we cannot solve this system without knowing the particular functional form of both $f_{B}$ and $g_{B}$.

We stress that the first equation in (7) is exactly the same that can be obtained from combining the two equations in (3); the only difference is due to the presence of mobility.

\subsection{Equilibrium}

The equilibrium with the soft budget constraint is identified by finding $q, I$, $b_{A}$, and $b_{B}$ that simultaneously satisfy the FOC's for $A$ and $B$, i.e. (6) and (7). Here, since we have defined $S_{A}=Q_{A}+I$ and $S_{B}=Q_{B}-I$, the solution already clears the market. Accordingly, the value of $q$ can be freely chosen by the Central Government ${ }^{8}$.

\footnotetext{
${ }^{8}$ Some health care systems (Italy among them) have set $q$ at national level, but it might become a strategic variable in the game between local authorities. For this reason, in our model we use it as a strategic variable.
} 
Thus, the system that must be solved is:

$$
\left\{\begin{array}{c}
b_{A}=v_{A}-f_{A}^{\prime}, \\
\rho q_{\frac{Y_{A}}{Y_{A}+Y_{B}}}+q-g_{A}^{\prime}=v_{A}-f_{A}^{\prime}, \\
b_{B}=v_{B}-f_{B}^{\prime}, \\
-\rho q \frac{Y_{B}}{Y_{A}+Y_{B}}-g_{B}^{\prime}=v_{B}-f_{B}^{\prime} .
\end{array}\right.
$$

Since the total amount of health care demanded is given by

$$
Q_{A}+Q_{B}=1-\frac{b_{A}+b_{B}}{2 \beta},
$$

in equilibrium we have

$$
Q_{A}+Q_{B}=1-\frac{\rho \frac{Y_{A}-Y_{B}}{Y_{A}+Y_{B}}+1}{2 \beta} q+\frac{g_{A}^{\prime}+g_{B}^{\prime}}{2 \beta} .
$$

This means that the total amount of supply and demand is:

1. negatively affected by $q$ (we recall that $Y_{A}>Y_{B}$ ): if the Central Government decides to set a high value of mobility cost, then mobility of course reduces;

2. negatively affected by $\rho$ : if the Local Authorities are more subject to fiscal illusion, then the total amount of production reduces; we stress that the fiscal illusion affects the production and demand via the revenue inequality, in fact if $Y_{A}=Y_{B}$, then $\rho$ does not affect the final amount of health care produced;

3. positively affected by the marginal spillover measured by $g_{i}^{\prime}$ : if the spillover from treating patients outside their own Region is more increasing, then the total health care produced is higher;

4. not affected by the local public good aspect measure by $f_{i}^{\prime}$ or the marginal production costs $v_{i}$, because of the compensation between Regions, due to mobility.

In the final outcome, Local Authority $A$ is budget balanced and $B$ reduces its level of taxation. The solution depends on the value of $\rho$, i.e. fiscal illusion. If there is perfect fiscal illusion (i.e. $\rho=0$ ) the constraint on $b_{B}$ is binding and any citizen in $B$ receives health care irrespective of its effectiveness. In $A$ some people are still constrained and are those for whom health care has a very low level of effectiveness. Mobility is rather high as is the deficit.

\section{Empirical evidence}

In this section we propose to test for the hypothesis that has been presented in the previous sections. To do so we use a balanced panel of data for the period 
2002-2006 for the Italian Regions. The theoretical model predicts that the presence of a soft budget constraint depends on fiscal illusion and a bargaining between the relatively richer and efficient local authorities and the poorer and less efficient ones. In our theoretical model we show that rich Local Authorities control the deficit of the relatively poorer ones through mobility and that the former should be equal to the latter. Actually, such a perfect correspondence between deficit and negative mobility may be more spurious because of several factors:

1. some Regions may use mobility for other scopes as shown in section 2 . In this case mobility of patients does not produce a deficit;

2. asymmetry in fiscal illusion or in the degree of vertical competition among Local and Central Governments. As shown in the previous section, this parameter influences the degree by which richer Regions allow poorer ones to run into a deficit.

We propose to test for the presence of bargaining using the following model:

$$
R D_{i t}=a_{t}+\beta_{1} R M_{i t}+\beta_{2} R G D P_{i t}+\beta_{3} R F S N_{i t}+\varepsilon_{i t},
$$

where

1. $R D$ is the ratio of the deficit to total expenditure;

2. $R M$ is the ratio of expenditure for mobility to total expenditure;

3. $R G D P$ is the ratio of GDP to average GDP;

4. RFSN is the ratio of the equalisation grant received by Central Government to total revenue.

The variable $R G D P$ is a measure of fiscal capacity and is meant to capture expectations about the effect that the soft budget constraint will have on net income of the Local Authorities. The deficit will in fact be covered using national taxes and the Regions with a tax base lower than average will expect to pay less than the others. This variable may also capture a different attitude to Local Authorities deriving from an asymmetry in fiscal illusion.

Even if the theoretical model considers the ratio between local GDP and total $\operatorname{GDP}\left(\frac{Y_{B}}{Y_{A}+Y_{B}}\right)$, here we prefer to use the ratio of GDP to average GDP because in our example, given that we are dealing with 21 different Local Authorities, this ratio is deemed to be a very small number. It is however important to note that we use total instead of per capita GDP in order to capture more efficiently the idea of shifting on other Local Authorities the burden of Regional health care.

Given that a national level taxation is progressive, we have inserted also the square of this variable $\left(R G D P^{2}\right)$ in the estimation procedure and tested for its 
inclusion as a regressor. To test for the presence of asymmetry in fiscal illusion we have also inserted two slope dummies:

$$
\begin{aligned}
& D R G D P= \begin{cases}0 & \text { if } R G D P>1 \\
R G D P & \text { if } R G D P \leq 1\end{cases} \\
& D R G D P^{2}= \begin{cases}0 & \text { if } R G D P>1 \\
R G D P^{2} & \text { if } R G D P \leq 1\end{cases}
\end{aligned}
$$

In the theoretical model mobility variable is set by the richer local authority; we can then expect an asymmetry in the relationship between deficit and mobility; for the local authorities that have a positive mobility, this may be a way to improve the budget balance; for those that run in a deficit mobility may not be used to further increase the deficit. Our theoretical model in fact predicts that richer Regions control the deficit of the other ones through mobility. To test for this asymmetry we introduce the slope dummy $D R M$ as follows

$$
D R M= \begin{cases}0 & \text { if net mobility }>0 \\ R M & \text { if net mobility } \leq 0\end{cases}
$$

Finally $R F S N$ is a measure of fiscal responsibility. The higher the proportion of public expenditure is financed using grants, the less local authorities will be accountable for their deficits.

The choice of using ratios instead of the variables themselves can be justified on several grounds: Regions vary in income and population, so the variables in levels do not allow to define the extent of the phenomenon we want to study; given that our estimation runs over six years, we should take into account both inflation and public expenditure but there is no consensus in the literature on which is the appropriate deflator. Deficit and mobility have been divided by total expenditure instead of total revenue. For the deficit, this choice does not need any further explanation. For mobility another candidate could have been total revenue. In fact, for Regions that have a negative mobility, the latter represents a part of expenditure, but for Regions that have a positive mobility, it represents a source of revenue. However, given that Regions with positive mobility have also their accounts quite close to balance, the use of expenditure instead of total revenue is not making any difference. The complete model to be estimated can be written as:

$$
\begin{aligned}
R D_{i t}= & a_{t}+\beta_{1} R M_{i t}+\beta_{2} D R M_{i t}+\beta_{3} R F S N_{i t}+\beta_{3} R G D P_{i t} \\
& +\beta_{4} D R G D P_{i t}+\beta_{5} R G D P_{i t}^{2}+\beta_{6} R G D P_{i t}^{2}+\varepsilon_{i t} .
\end{aligned}
$$

The definition of the variables used, the data sources and the most relevant descriptive statistics are presented in table 1.

\section{TABLE I}


A pool cross section estimation has been run using fixed effects and the results are summarised in table 2 .

\section{TABLE II}

We have tested for the inclusion of RFSN, and the dummies on $R G D P$ by running separate regressions that exclude these variables. In both cases the $\log$-likelihood ratio and the $t$ test show that the variables we have included are significant.

The model fits the data quite well; about $84 \%$ of the variance is captured by our model and for the form we have chosen the LM test accepts the hypothesis of homescedastic residuals. The relationship between mobility and deficit is confirmed and has the right sign. The model also confirms the tight control that Regions without a deficit exercise on the other ones. The relationship between deficit and mobility is very close to zero when mobility is negative.

The sign for the relationship between GDP and deficit may seem a bit puzzling; for the local authorities that do not run into a deficit the signs are as expected while for the ones that have negative balance it may seem that the relationship goes in the wrong direction. However, although it is true that the variables have "the wrong sign", the combined effect of both variables simply means that the GDP has a much lower impact, although significant, in debt formation. There are two possible explanations for this effect: the first comes from the observation of the data: a significant number of local authorities that run into a deficit have a very low GDP ratio: for them it is possible to shift the tax burden of their expenditure to the rest of the economy. The expected impact is however very limited: the relationship is U-shaped and it maximum effect is -0.006 (i.e. an increase in the deficit ratio by 0.006 ).

This asymmetry in the behaviour is certainly important as shown by the last column in table 2. When the dummies on GDP are not included, the variable has "the wrong sign" and the interpretation of the relationship between mobility and deficit is not so clear.

\section{Conclusions}

In the recent past the process of fiscal federalism has meant the use of devolution in the provision of goods and services that are both impure public goods and merit goods, i.e. they are rival in consumption and can be supplied to local residents also by providers located outside the boundaries of the local authority.

However, in some countries devolution has not produced the desired effects. The control over expenditure growth has not always been successful and, something even more important for EU countries, regional deficits related to health care expenditure have started to increase.

In this paper we show that the use of fiscal federalism in health care may produce perverse effects because both richer (and more efficient) Local Authorities and poorer (and less efficient) ones may have an interest in playing strategically. The former want to control expenditure, the latter have no incentive to raise 
resources locally and to become more efficient. We use an approach similar to the one developed in Levaggi and Menoncin (2009) to show that a soft budget constraint policy is the likely outcome of a process of fiscal federalism when applied to health care provision.

Both the theoretical model and the empirical estimation prove the existence of a bargaining process between rich, oversized Regions and poor one which agrees to increase expenditure and loosen their constraints using this policy.

In the short run this may be the best way to react to tighter controls, but the effects of a soft budget constraint are perverse: total welfare is lower, and Central Government is not able to control total expenditure and the distribution of welfare between the two Regions.

From 2007 in Italy, Central Government has tightened the budget rules. The Regions that have a deficit have to present a plan (Piano di Rientro) to explain how they will reduce their deficits; if they do not comply, Central Government may directly increase their tax rate to meet expenditure. The empirical evidence on the effects of this policy is still to scant to be evaluated, but it is certainly moving, at least from a theoretical point of view, in the right direction.

We have presented Italy as a case study to show the relevance of our hypothesis, but the same setting can be used in other federal contexts where resources are unevenly distributed and preferences are not homogeneous. 


\section{References}

[1] Bordignon, M and G Turati (2009) Bailing Out Expectations and Health Expenditure in Italy: an empirical approach, Journal of Health Economics, 28(2), 305-321

[2] Besley, T. and S.Coate (2003) Centralized versus decentralised provision of local public goods: a political economy approach, Journal of Public Economics, 87,2611-37

[3] Crivelli E and K Staal (2008) Size, Spillovers and Soft Budget Constraints, Working Paper Series of the Max Planck Institute for Research on Collective Goods 2008_17, Max Planck Institute for Research on Collective Goods.

[4] Ferrario C. and A. Zanardi (2009), From interpersonal to interregional redistribution: the case of social policies in Italy, forthcoming in E. Ongaro, A. Massey, M. Holzer and E. Wayenberg (eds.) "Governance and Intergovernmental Relations in the European Union and the United States: Policy and Management", Edward Elgar, Cheltenham, UK

[5] Marton, J and D Wildasin (2007). Medicaid Expenditures and State Budgets: Past, Present, and Future, Working Papers 2007-04, University of Kentucky, Institute for Federalism and Intergovernmental Relations.

[6] Maskin, E and C Xu (2001) Soft Budget Constraint Theories, Economics of Transition, 9, 1-27.

[7] Kornai J, (1986), The Soft Budget Constraint, Kyklos, 39(1), 3-30.

[8] Kornai, J, E Maskin and G Roland (2003) "Understanding the Soft Budget Constraint," Journal of Economic Literature, XLI, 1095-1136.

[9] Levaggi, R and R Zanola (2003) Flypaper Effect and Sluggishness: Evidence from Regional Health Expenditure in Italy, International Tax and Public Finance, 10(5),537-547

[10] Levaggi, R and F Menoncin (2008) Fiscal federalism, patients' mobility and the soft budget constraint: a theoretical approach, Politica Economica, $26(3), 367-379$

[11] Levaggi, R and F Menoncin (2009) Decentralised Provision of Merit and Impure Public Goods. Available at SSRN: http://ssrn.com/abstract=1194923

[12] Oates, W (2005) Towards a second generation Theory of Fiscal Federalism, International Tax and Public Finance, 12, 349-374

[13] Petretto, A (2000) On the cost and benefit of the regionalisation of the NHS, Economics of Governance, 1, 213-232 
[14] Rodden J. (2003) Soft budget constraint and the German Federalism, in Rodden J. (eds) Fiscal Decentralisation and the challenge of Hard Budget Constraints, MIT Press, Boston, US

[15] Saltman, B.R. and Figueras, J. (1997) European health care reform: analysis of current strategies.WHO Regional Publications, European series, n.7, Copenhagen, Denmark

[16] Sandmo, A. (1998) Redistribution and the marginal cost of public funds. Journal of Public economics

[17] Tresh, R (2002) Public Finance: A normative view, 2nd Edition, Academic Press, San Diego

[18] Wildasin , DE (2004) The institutions of federalism: towards an analytical framework, National Tax Journal, LVII, 247-272

[19] Wildasin , DE (1997) Wildasin, D.E. (1997) Externalities and bailouts, Hard and Soft budget constraints in Intergovernmental Fiscal Relations, mimeo 
Figure 1: Mobility balance and Regional deficit in Italy

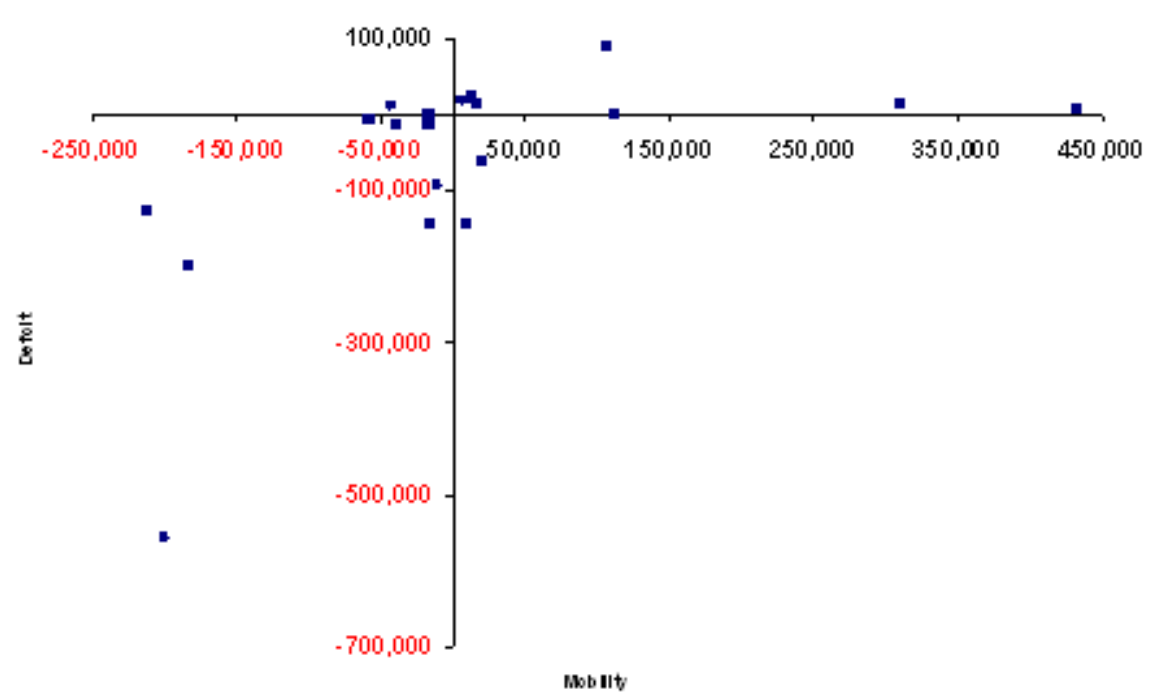


Table 1: Descriptive statistics for data used in the regressions

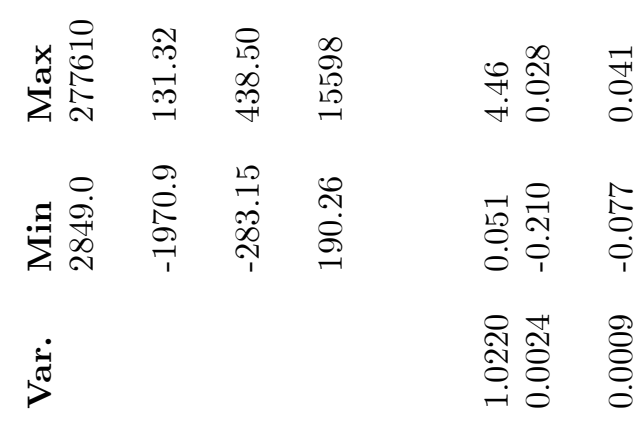

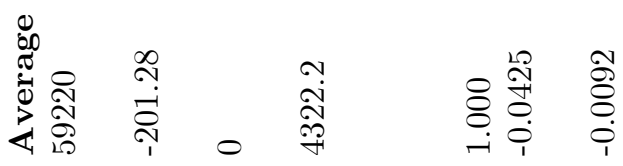

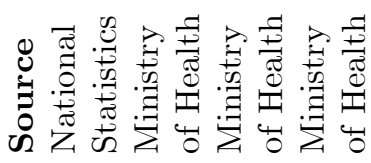

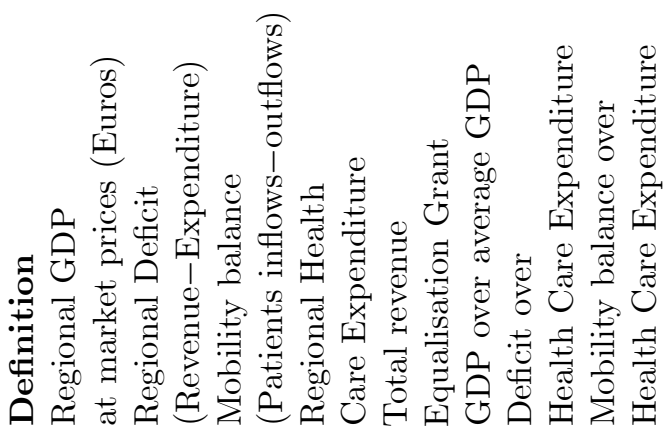

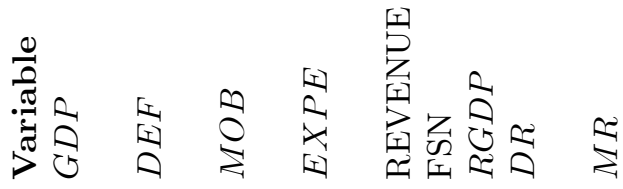


Table 2: The relationship between mobility and deficit

$\begin{array}{llll} & \text { I } & \text { II } & \text { III } \\ R G D P & 0.051(5.49) & 0.059(6.33) & -0.018(2.62) \\ D R G D P & -0.063(8.52) & -0.072(9.08) & \\ R G D P^{2} & -0.010(4.67) & -0.011(4.95) & 0.0028(1.84) \\ D R G D P^{2} & 0.012(5.78) & 0.013(6.17) & \\ R M & 0.78(5.04) & 0.74(5.26) & 0.71(2.84) \\ D R M & -0.79(4.23) & -1.13(5.93) & -0.29(1.96) \\ R F S N & -0.09(4.26) & & -0.16(5.77) \\ \mathrm{N} & 105 & 105 & 105 \\ \text { BUSE } \mathrm{R}^{2} & 0.841[0.698]^{* *} & 0.785[0.607] & 0.624[0.315] \\ \mathrm{LL} & 253.6 & 248.0 & 230.0 \\ \text { LM } & 20.26 & 37.62 & 36.42 \\ * \text { in brackets the Student's } t \text { asymptotic ratio } & \\ \text { ** in square } & \text { brackets the within transformation } & R^{2}\end{array}$

